\title{
Impact Assessment of Land Use Change on Ground Water Quality Using Remote Sensing \& GIS for Zone V under Municipal Corporation Hyderabad
}

\author{
Gogana Venkateswarlu ${ }^{1 *}$, G Jayasankar ${ }^{2}$, B.V Saradhi ${ }^{3}$ \\ ${ }^{I}$ (Associate Professor, Department of Civil Engineering Anurag Group of Institutions, JNTU Hyderabad, India) \\ ${ }_{2}^{2}$ Professor, Department of Geo-Engg \& Cente for Remote Sensing, College of Engg(A), A.U, Vizag, India) \\ ${ }^{3}$ (Professor, Department of Civil Engineering, Andhra University, Vizag, India)
}

\begin{abstract}
Water is essential to people and the largest available source of fresh water lies underground. Increased demands for water have stimulated exploration of underground water resources. As a result techniques for investigating the occurrence and movement of ground water have been improved, better equipment for extracting ground water has been developed, concepts for Research Management have been established and research has contributed to a better understanding of the subject. In present study an attempt is made to evaluate the impact of land use/land cover on ground water quality of Zone $V$ under Municipal Corporation of Hyderabad (MCH) area. Ground water samples were collected at pre-determined sampling locations based on Satellite Imagery of the study area. All the samples were analyzed for various physicochemical parameters adopting standard protocols for the generation of attribute data. Based on the results obtained maps showing spatial distribution of selected water quality parameters are prepared using curve-fitting method in GIS Software. Water quality index (WOI) in the study area is calculated to determine the suitability of ground water for drinking purpose.
\end{abstract}

Keywords: Curve fitting method, GIS software, Remote Sensing, Satellite Imagery, Water quality index

\section{Introduction}

Remote sensing and GIS are playing a rapidly increasing role in the field of hydrology and water resources development. Remote sensing provides multi-spectral, multi-temporal and multi-sensor data of the earth's

surface (Choudhury, 1999). One of the greatest advantages of using remote sensing data for hydrological investigations and monitoring is its ability to generate information in spatial and temporal domain, which is very crucial for successful analysis, prediction and validation (Saraf, 1999) However, the use of remote sensing technology involves large amount of spatial data management and requires an efficient system to handle such data. The GIS technology provides suitable alternatives for efficient management of large and complex databases. Information from satellites is becoming more and more important for environmental research. An important part of this information concerns water an element most essential for man, its phases and peculiarities. In general, water resources in India are very unevenly distributed both spatially and temporally. Idiosyncrasy of monsoon and diverse physiographic conditions give rise to unequal distribution of water. Over the years, increasing population, urbanization and expansion in agriculture and domestic water utilization has accentuated the situation. The present study is aimed to understand some of the crucial problems of groundwater quality and management with the help of latest available techniques in an integrated manner. The proposed study will certainly fill the crucial gap of knowledge related to the salinity problem by providing detailed field and laboratory data with GIS analysis for proper interpretation. According to conserve to next generation people to consider going the present work is an attempt towards this direction. The study focuses on development of remote sensing and GIS based analysis and methodology in groundwater recharge studies in watershed. In order to demonstrate the Role of remote sensing and GIS based methodology, the Impact assessment of land use change on ground water quality using remote sensing \& GIS for zone V under municipal corporation Hyderabad. Introduction of the paper should explain the nature of the problem, previous work, purpose, and the contribution of the paper. The contents of each section may be provided to understand easily about the paper.

A. Study Area: The city lies between $78^{\circ} 22^{\prime} 30$ and $78^{\circ} 32^{\prime} 30$ East Longitude and between $17^{\circ} 18^{\prime} 30$ and $17^{0} 28^{\prime} 30$ North Latitude. The city is situated in the Krishna Basin and River Musi, which is a tributary of river Krishna, is passing through the city of Hyderabad and bifurcates the city as North and South Hyderabad. Out of the $\mathrm{MCH}$ area Zone- $\mathrm{V}$ extends at $78^{\circ} 26.49^{\prime} \mathrm{W}$ latitude and $17^{\circ} 24.5^{\prime} \mathrm{N}$ longitudes with a total area of 18.309 Sq. Km which is selected for the present investigations. 


\section{Aim And Objectives}

The basic aim of present study is to conduct the remote sensing and GIS technology in order to identify the suitable sites for artificial recharge zones with an integrated approach of remote sensing and GIS approach techniques which are being followed by these objectives. To use of remote sensing and GIS technique in groundwater recharge investigations in sub watershed. To prepared the groundwater potential zones in the sub watershed. To identify the interrelationships of recharge areas with geology, geomorphology, soils and structure of the sub watershed. To suggest suitable sites and methods for artificial recharge to augment groundwater recharge with Village Tank, cement nala bund etc. in the sub watershed.

A. Aim of the subject: Rapid urbanization and industrialization has led to unchecked proliferation of hazardous industries in and around Hyderabad, unchecked and unregulated distribution and management of urban resources especially green areas, water bodies and the combination of above aspects with large scale urban sprawl have all made Hyderabad an unmanaged polluting city. One of the major problems 'Water Pollution' is referred to the addition to water an excess of material that is harmful to humans, animals, or desirable aquatic life, or otherwise causes significant departures from the normal activities of various living communities, in or near bodies of water. The term water pollution refers to any type of aquatic contamination between two extremes:

1) A highly enriched over productive biotic community such as river, lake with nutrients from fertilizer.

2) Water body poisoned by toxic chemicals, which eliminates living organizing exclude all forms of life.

B. Objectives: The main objective of the study is utilization of integrated methodology, which derives a correlation between land use/ land recover and water quality parameters.

1) Assessment of impact of land use/ land cover on ground water quality in the present study ( Zone V).

2) To analyze the estimated ground water quality in the study area for its suitability for drinking purpose.

3) Determination of water quality index by statistical approach.

4) To highlight the areas under environmental stress.

5) To recommend suitable measures for best management mitigation process.

\section{Designing And Methodology}

The methodology or the work scheduled gives the following principles steps involved, which are to be adhered, to achieve the set of objection.

a) Collection of toposheet from survey of India (1:50000 scale).

b) Collection of data from satellite imagery ( fused data of IRS-RS2 Imagery) obtained from NRSC,

Balanagar.

c) Delineation of the study area ( Based on $\mathrm{MCH}$ division) and conversion of raster data into vector data.

d) Preparation of thematic maps with the help of secondary data and primary data.

e) Study of the land use features and their influence on the zone.

f) Analyzing the quality of water and top determine water quality index by rating the parameters. g)

Correlating the land use impact with the water quality.

h) Resulting with the previous data for the comparative study and to find the changes.

i) Recommendations at micro level.

A. $\quad$ Sources of Data Products:

\begin{tabular}{|c|l|l|}
\hline S.No & Thematic Layers & Source of Acquisition \\
\hline 1 & $\begin{array}{l}\text { Land use/ Land recover } \\
\text { (Level II classification) }\end{array}$ & $\begin{array}{c}\text { Satellite Data from NRSC } \\
\text { (IRS-RS2 LISS 4 FMX, Resolution }\end{array}$ \\
\hline 2 & Map showing Darinage & Survey of India Toposheet \\
\hline 3 & Map showing & Survey of India Toposheet \\
\hline
\end{tabular}


B.

\section{Limitation:}

a)

b) Study is limited to study zone.

The selection of environmental parameters and land use features are confined to data availability and

c) time constraint.

Recommendations are not suggested at macro level.

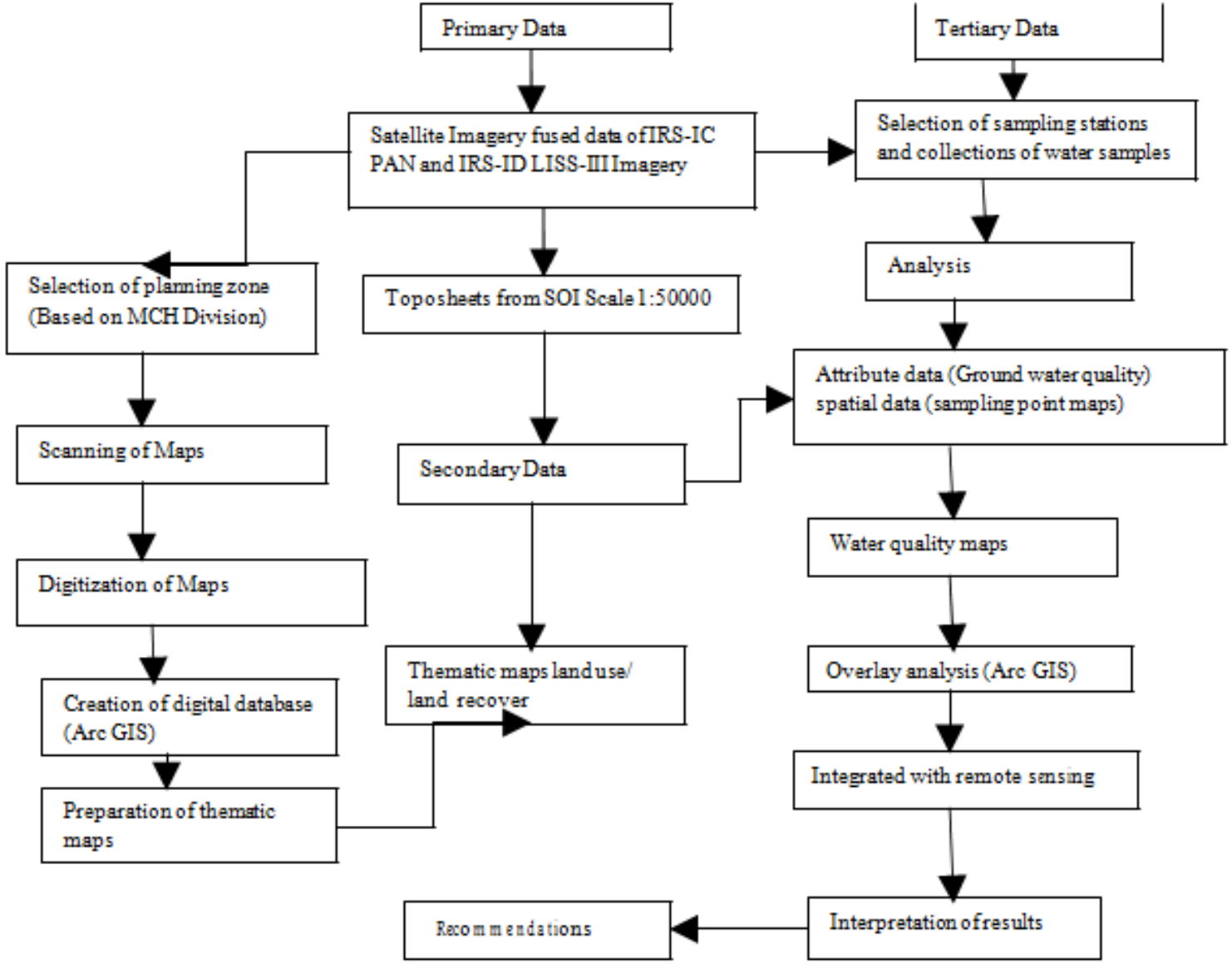

Figure 1. Flow chart showing the methodology adopted for the generation of database

\section{Database creation:}

IRS-ID PAN and LISS-III satellite imageries are georeferenced using the ground control points with SOI toposheets as a reference and further merged to obtain a fused, high resolution (5.8m of PAN) and colored (R,G,B bands of LISS-III) output in EASI/PACE v6.3 Image processing software. The study area is then delineated from the fused data based on the latitude and longitude values and a final hard copy output prepared which is further interpreted visually for the generation of thematic maps. These thematic maps (Raster data) are converted to vector format by scanning using an A0-Flatbed Deskjet scanner and digitized in AUTOCAD 2000. The map is further edited in ARC/INFO v3.5.1 and final hardcopy output is prepared using ARC/VIEW v3.1 GIS software. The methodology adopted for creation of database is given in Fig.1.

\section{Spatial index:}

Thematic maps like base map and drainage network maps are prepared from the SOI toposheets on 1:50,000 scale using AutoCAD and Arc/Info GIS software to obtain a baseline data. All the maps are scanned and digitized to generate a digital output. Land use/Land cover map of the study area was prepared using visual interpretation technique from the fused satellite imagery (IRS-ID PAN + LISS-III) and SOI toposheets along with ground truth analysis.

\section{E. Attribute database:}

Fieldwork was conducted and groundwater samples were collected from predetermined locations based on the 
land use change and drainage network maps of the study area. Map showing sampling points overlaid on satellite imagery as shown in Fig 2. The water samples were then analyzed for various physico-chemical parameters adopting standard protocols [5].

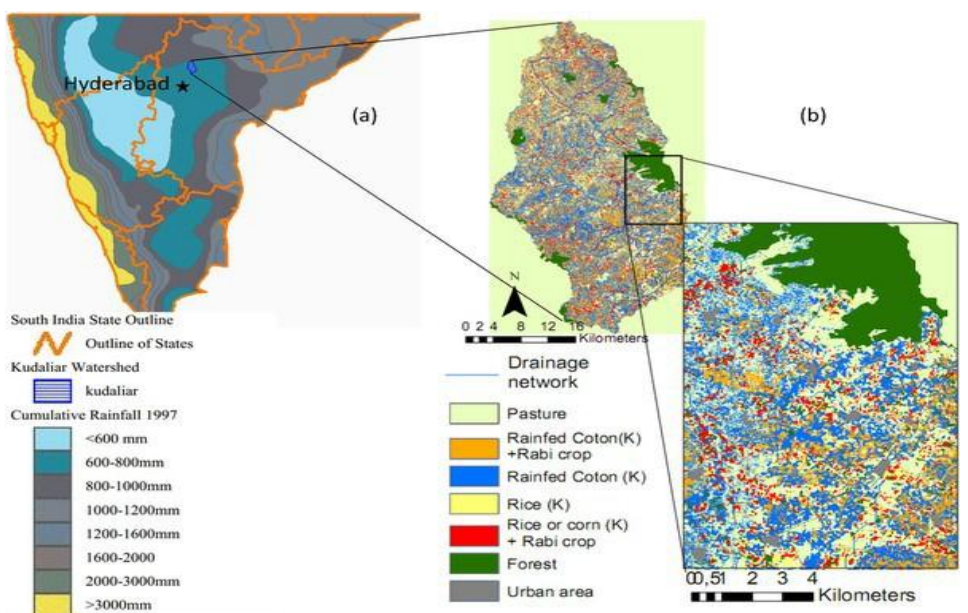

Figure 2. Map showing sampling points overlaid on satellite imagery

\section{F. Integration of Spatial and Attribute Database:}

The spatial and the attribute database generated are integrated for the generation of spatial distribution maps of selected water quality parameters like $\mathrm{pH}$, alkalinity, chlorides, sulphates, nitrates, TDS, total hardness, fluorides and Water Quality Index (WQI) and overlaid on satellite imagery. The water quality data (attribute) is linked to the sampling location (spatial) in ARC/INFO and maps showing spatial distribution are prepared to easily identify the variation in concentrations of the above parameters in the ground water at various locations of the study area using curve fitting technique of ARC/VIEW GIS software.

\section{G. Spatial Modeling and Surface Interpolation through IDW:}

GIS can be a powerful tool for developing solutions for water resources problems for assessing water quality, determining water availability, preventing flooding, understanding the natural environment, and managing water resources on a local or regional scale [6]. Though there are a number of spatial modeling techniques available with respect to application in GIS, spatial interpolation technique through Inverse Distance Weighted (IDW) approach has been used in the present study to delineate the locational distribution of water pollutants or constituents. This method uses a defined or selected set of sample points for estimating the output grid cell value. It determines the cell values using a linearly weighted combination of a set of sample points and controls the significance of known points upon the interpolated values based upon their distance from the output point thereby generating a surface grid as well as thematic isolines. Important water quality indicating parameters and their distribution patterns were studied in Hyderabad metropolis also with the help of cartographic techniques. Thus, GIS enables us to look into the cause and effect relationship with visual presentation [7].

\section{H. $\quad$ Estimation of Water Quality Index (WQI):}

Water Quality Index (WQI) is a very useful and efficient method for assessing the quality of water [8]. Water Quality Index (WQI) is a very useful tool for communicating the information on overall quality of water [9, 10]. To determine the suitability of the groundwater for drinking purposes, WQI is computed adopting the following formula [11].

$$
\mathrm{WQI}=\text { Antilog }\left[\mathrm{W}_{\mathrm{n} n=1} \log _{10} \mathrm{q}_{\mathrm{n}}\right]
$$

where, $\mathrm{W}$, Weightage factor $(\mathrm{W})$ is computed using the following equation

$$
\mathrm{W}_{\mathrm{n}}=\mathrm{K} / \mathrm{S}_{\mathrm{n}}
$$

and $\mathrm{K}$, Proportionality constant is derived from,

$$
\mathrm{K}=\left[1 /\left(\mathrm{n} n=11 / \mathrm{S}_{\mathrm{i}}\right)\right]
$$


$\mathrm{S}_{\mathrm{n}}$ and $\mathrm{Si}$ are the WHO / ICMR standard values of the water quality parameter. Quality rating (q) is calculated using the formula,

$$
\mathrm{q}_{\mathrm{ni}}=\left\{\left[\left(\mathrm{V}_{\text {actual }}-\mathrm{V}_{\text {ideal }}\right) /\left(\mathrm{V}_{\text {standard }}-\mathrm{V}_{\text {ideal }}\right)\right] * 100\right\}
$$

where, qni $=$ Quality rating of ith parameter for a total of $n$ water quality parameters

Vactual $=$ Value of the water quality parameter obtained from laboratory analysis

Videal $=$ Value of that water quality parameter can be obtained from the standard tables. Videal for $\mathrm{pH}=7$ and for other parameters it is equalent to zero.

Vstandard $=$ WHO / ICMR standard of the water quality parameter Based on the above WQI values, the ground water quality is rated as excellent, good, poor, very poor and unfit for human consumption

\section{Experimental Results}

An analysis of the nature and rate of land use change and its associated impact on groundwater quality is essential for a proper understanding of the present environmental problems [12]. In the present study area, built- up land includes dense, medium and sparse residential areas, which comprises of $18.88 \mathrm{~km} 2$ of the total study area out of which $9.74 \mathrm{~km} 2$ is of dense residential and $4.73 \mathrm{~km} 2$ medium residential and $4.57 \mathrm{~km} 2$ sparse residential areas as shown in Fig 3 and Fig 4.

The $\mathrm{pH}$ of the water samples in the study area ranged in between $6.0-8.0$. High alkaline water with concentrations ranging above 300mg/l was observed at Yellareddyguda and Erragadda, which is due to decay of organic matter, weathering of rocks and minerals. The concentration of chloride in most of the areas is within the permissible limits except at Banjara Hills N.V.T. Nagar, which has $260 \mathrm{mg} / 1$ of chloride. The highest concentration of total dissolved solids was found to be $1350 \mathrm{mg} / \mathrm{l}$ at Erragadda and at Yellareddyguda with $1010 \mathrm{mg} / \mathrm{l}$ which is due to the presence of dense residential area and due to BSA land form. Solid waste dumping site situated at Yousufguda and locations of industries at Sanath Nagar have an impact on the groundwater of these areas. A high concentration of TDS was also observed at Southern Jubilee Hills (1245mg/l) and Sheikpet $(1120 \mathrm{mg} / \mathrm{l})$, which is attributed to agricultural practices (Fig. 5). TDS in ground water also originate from natural sources, sewage, urban run-off and industrial wastes [10].

Water Quality index is calculated to determine the suitability of water for drinking purpose [18 \& 19]. Water quality index values revealed that the ground water at six locations of the study area was of good quality with

the WQI ranging in between 0-50 and therefore can be used for human consumption. Eight samples were of poor quality with WQI ranging in between 50-75 and six samples were of very poor quality and cannot be used for domestic purposes. The WQI was found to be above 100 in areas like NVT Nagar and Road No.10 of Banjara Hills, Yellaredduguda, Erragadda and Motinagar and therefore cannot be used for human consumption. The WQI map is shown in Fig 6.

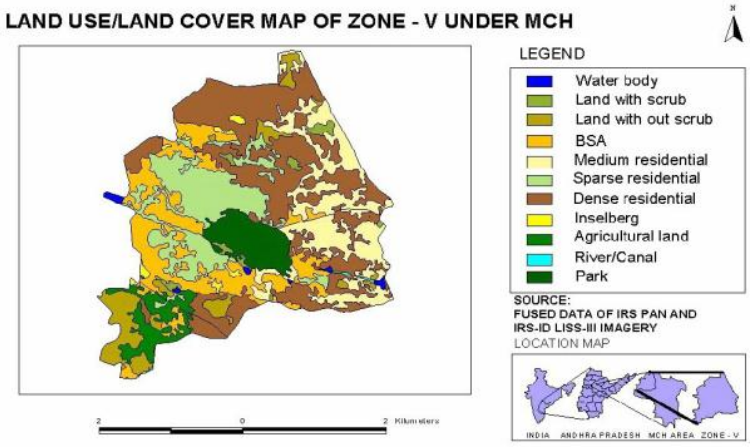

Figure 3. Land use / Land cover Map

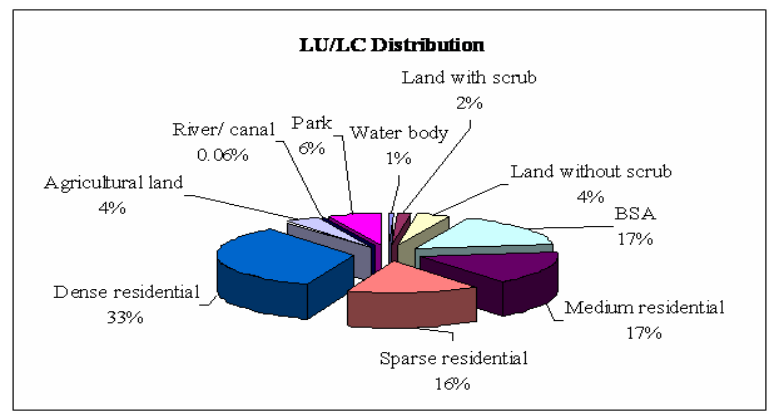


Figure 4. Land use / land cover distribution in the study area

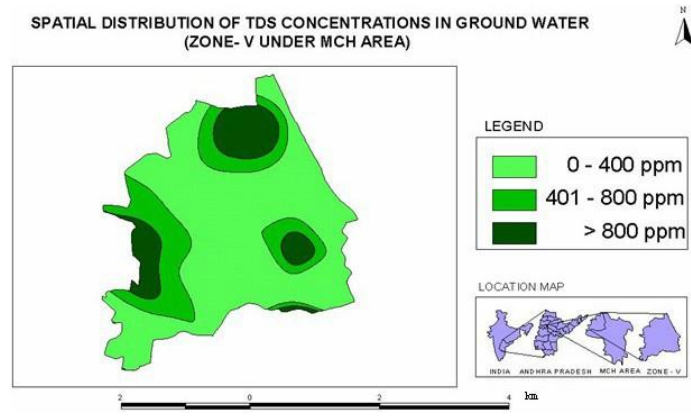

Figure 5. Spatial Distribution of Total Dissolved Solids

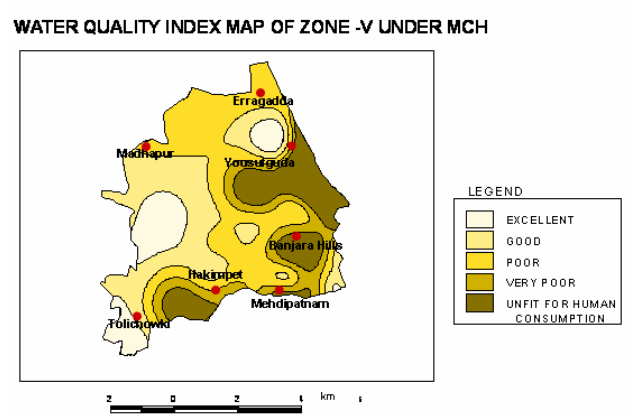

Figure 6. Water Quality Index Ma

\section{Conclusion}

The water quality Index can be a very special and efficient tool for communicating the information on overall quality of water, in present study the water quality rating in $\mathrm{MCH}$ Zone V varied from good, poor, very poor to poor for human consumption. The water quality of a place may be related to land use in that area. The more land use more will be environmental degradation. From the land use/ land covert and waer quality index obtained in the present study. It is observed that water quality deteroited. Residential and commercial areas are reasonably good except Golnaka which showed high value of fluride. Monitoring of pollution patterns and its trends with respect to urbanization is an important task for achieving sustainable management of groundwater. An integrated Remote sensing and GIS study proves to be an essential tool to evaluate and quantify the impacts of land use / land cover on ground water quality. Spatial distribution maps of various pollution parameters are used to demarcate the locational distribution of water pollutants in a comprehensive manner and help in suggesting groundwater pollution control and remedial measures in a holistic way.

\section{References}

[1] Gyananath, G.; Islam, S.R.; Shewdikar, S.V. Assessment of Environmental Parameter on ground water quality. Indian Journal ofEnvironmental Protection. 2001, 21, 289-294

[2] Directorate of Census Operations. District Census Handbook of Hyderabad, 1991, Andhra Pradesh, Census of India.

[3] Skidmore, A.K.; Witske Bijer; Karin Schmidt; Lalit Kumar, K. Use of Remote sensing and GIS for sustainable land management. ITC Journal. 1997, 3 (4), 302-315.

[4] Ferry Ledi Tjandra; Akihiko Kondhoh; Mohammed Aslam M.A. A Conceptual Database Design For Hydrology Using GIS.Proceedings of Asia Pacific Association of Hydrology and Water Resources. March 2003, 13-15, Kyoto, Japan.

[5] APHA, AWWA, WPCF. Standard Methods for the Examination of Water and Wastewater. 20th edition, American Public Health Association, Washington, DC, New York, USA, 1998.

[6] Collet, C.: Geographic Information System Needs and Software. Kluwer Academic Publishers, Boston, USA, 1996

[7] Mudassar Hassan Arsalan. A GIS appraisal of Heavy metals concentration in Soil. GIS @ Development. Published by the American Society of Civil Engineers, 345 East 47 Street: New York 10017- 2398, 2004, 8(4).

[8] Abassi, S. A.: Water Quality Indices, State-of-the art. J.IPHE. 1999, No.1.

[9] Pradhan, S. K.; Dipika Patnaik; Rout, S. P.: Water quality index for the ground water in and around a phosphatic fertilizer plant. Indian. Journal of Environmental Protection. 2001, 21, 355-358.

[10] Mahuya Das Gupta Adak; Purohit, K. M.; Jayita Datta.: Assessment of drinking water quality of river Brahmani. Indian Journal of Environmental Protection. 2001, 8(3), 285-291. 


\section{Author Profile}

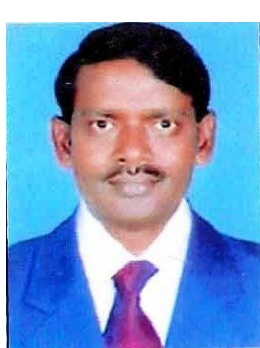

topics.
Gogana Venkateswarlu is presently a research scholar in the department of Civil \& Geo Engineering from Andhra University, Vishakapatnam, A.P, India. Presently he is working as an Associate professor in the department of Civil Engineering at Anurag Group of Institutions, JNTU Hyderabad. During his work in his profession he has been achieved great honor like he has been awarded Bharat Jyothi Award in Science and Technology - December 2008, UGC- Junior Research Fellowship - March 2004, CSIR - Senior Research Fellowship - April 2004, and he has got membership in Indian Science Congress Association Kolkata and Registered Architect in Council of Architect, New Delhi.

He has been attended several International and National Conferences and presented several papers based on his research areas. He has published several International and National journals on his 